\title{
Política demográfica, crecimiento económico y formación del mercado laboral en el Perú del siglo veinte
}

\author{
Population Policy, Economic Growth and the Labor Market \\ Formation in $20^{\text {th }}$ Century Peru
}

\author{
CARLOS CONTRERAS \\ Departamento de Economía de la PUCP
}

\begin{abstract}
RESUMEN
El artículo presenta los determinantes locales de la política de población y de la evolución demográfica del Perú a lo largo del siglo veinte.

Para ello expone el proceso de formación del mercado laboral, en el contexto de un país en el que hasta finales del siglo diecinueve tres cuartas de la población vivían inmersas en un régimen autárquico, y cuyo sector comercial consistía en economías primarias de exportación diseminadas por el territorio de la república. Dentro del mundo latinoamericano, el Perú se caracterizó, primero, por sus altas tasas de natalidad y por tener un inicio más bien tardío de su transición demográfica, y segundo, por la acelerada disminución de su natalidad. En este trabajo se intenta explicar tanto los orígenes como las consecuencias económicas de esta
\end{abstract} trayectoria.

PALABRAS CLAVE: Población, Condiciones Económicas, Mercado Laboral, Perú, Siglo Veinte Códigos JEL: J20

\section{ABSTRACT}

This article presents the local determinants of the politics of population and of the demographic evolution from Peru along the twentieth century. For it exposes the process of formation of the labor market, in the context of a country in which to nineteenth-century ends three quarters of the population lived immersed in an auto subsistence regimen, and whose commercial sector consisted of primary economies of export disseminated by the territory of the republic. Inside the LatinAmerican world, Peru was characterized, first, by its high birth rates and by having a well latest start of its demographic transition, and second, by the rapid decrease of its birth rate. This work tries to explain so much the origins as the economic consequences of this path.

KEY WORDS: Population, Economic Conditions, Labour Market, Peru, 20th Century

JEL Codes: J20 


\section{Introducción ${ }^{1}$}

$\mathrm{E}$ n este artículo ofrecemos un panorama de la interrelación desarrollada entre la evolución económica y demográfica a lo largo del siglo veinte en el Perú, sobre la base de las estadísticas vitales y los censos nacionales realizados durante dicha centuria, y de la revisión de la bibliografía disponible ${ }^{2}$. Nuestro objetivo es mostrar las pulsiones internas sobre la evolución demográfica, a contra corriente de la tendencia dominante, que ha sido apreciar la demografía latinoamericana como determinada fundamentalmente desde el exterior. Partiendo de la idea que las presiones de la dinámica de la economía sobre el curso demográfico se expresarían a través de la política del Estado en materia de población, como de la propia conducta reproductiva de esta, nos concentraremos en enfocar ambos aspectos.

Dentro de la historia demográfica latinoamericana del siglo veinte, el Perú aparece como una nación "típica", con un ciclo de moderado descenso de la mortalidad en la primera mitad (que se vuelve más acusado al llegar a los mediados del siglo), y una reducción rápida de la natalidad en el último tercio. En el tema de la interrelación entre la evolución demográfica y el desempeño económico destaca por haber desafiado -junto con otros, como México, Colombia y Brasil- la llamada "trampa maltusiana", que predecía que las altas tasas de crecimiento demográfico en las sociedades pobres, impedirían su crecimiento económico en el largo plazo ${ }^{3}$.

Comenzaremos con una periodización de la interrelación entre las políticas económica y demográfica ocurrida en el Perú del siglo veinte, para dedicar luego un apartado a cada uno de los períodos que distinguimos en ello: uno de política demográfica expansiva, en el primer tercio del siglo; otro de política restrictiva y más bien

[Fecha de recepción del original, enero de 2008. Versión definitiva, julio de 2008]

1 Para esta investigación conté con el apoyo de Francis Chávez en el trabajo con los censos nacionales. Asimismo, agradezco a Marcos Cueto y Walter Mendoza, que me facilitaron bibliografía pertinente. Los comentarios de Carlos Eduardo Aramburú y Pedro Francke a una primera versión del texto, fueron de gran ayuda para corregir defectos y sugerir nuevas ideas. Asimismo, los de los comentaristas anónimos de la revista Investigaciones en Historia Económicas. Desde luego, esto no los hace responsables de los vacíos y limitaciones que puedan subsistir en el trabajo.

2 La idea de esta interacción entre población y economía, tiene un vasto linaje en las ciencias sociales, que arranca con Thomas Malthus (1798, fecha de su Ensayo sobre la población), y ha proseguido en tiempos más recientes, con autores como Coale y Hoover (1965), quienes argumentaron que mientras más elevado fuese el crecimiento demográfico menos recursos podrían destinarse al crecimiento económico, frenándolo en consecuencia. Otros autores, como Clark (1970), Boserup (1984), y Simon (1991), resaltaron en cambio las ventajas para el crecimiento económico que conllevó el aumento de la densidad demográfica.

3 En cambio, algunos países que siguieron mejor los preceptos maltusianos, exhibiendo un menor crecimiento demográfico en América Latina, como Argentina y Uruguay, tuvieron un peor desempeño económico en el siglo veinte. Ver Thorp (1998), cap. 2 y Merrick (1997). 
CUADRO 1

CRECIMIENTO DEMOGRÁFICO EN EL PERÚ Y AMÉRICA LATINA, POR CENTURIAS, SIGLOS XVI-XX

\begin{tabular}{lcccc}
\hline & \multicolumn{2}{c}{ Perú } & \multicolumn{2}{c}{ América Latina } \\
\hline Siglo & $\begin{array}{c}\text { Población al comenzar } \\
\text { el siglo, en millones } \\
\text { de habs. }\end{array}$ & $\begin{array}{c}\text { Tasa de crecimiento } \\
\text { anual en el siglo }\end{array}$ & $\begin{array}{c}\text { Población al comenzar } \\
\text { el siglo, en millones } \\
\text { de habs. }\end{array}$ & $\begin{array}{c}\text { Tasa de crecimiento } \\
\text { anual en el siglo }\end{array}$ \\
\hline XVI & 6,0 & $-1,9$ & 17,5 & $-0,7$ \\
XVII & 0,9 & $-0,2$ & 8,6 & 0,3 \\
XVIII & 0,7 & 0,5 & 12,0 & 0,5 \\
XIX & 1,2 & 1,1 & $21,2^{*}$ & 1,3 \\
XX & 3,6 & 2,0 & 61,0 & 2,2 \\
XXI & 25,6 & & 511,7 & \\
\hline
\end{tabular}

* Corresponde a 1820; en consecuencia la tasa de la última columna para el siglo XVIII corresponde al período 17001820, y para el siglo XIX, al período 1820-1900.

Fuentes: Perú: Varillas y Mostajo (1990), p. 23; Seminario-Beltrán (1998), p. 25; BCRP (2006), p. 196; América Latina: Maddison (2002), p. 35; Sánchez-Albornoz (1973), p. 192, y CEPAL (2006), p. 23.

centrada en el mejoramiento de la calidad de la población, en los mediados del siglo (1930-1975, como fechas aproximadas); y uno de política más bien represiva, en el último cuarto. Cerraremos con unas reflexiones generales.

\section{La transición demográfica en el Perú}

En América Latina el siglo veinte fue marcado por la transición demográfica. La caída de la mortalidad había comenzado ya en el siglo anterior en algunos casos (Argentina, Uruguay, Cuba) pero se volvió recién manifiesta en el resto de países en las primeras décadas (o aún en las de mediados) del veinte. El Perú, como las demás naciones indígenas americanas (México, los países centroamericanos y los andinos) se caracterizó por un inicio tardío de dicha transición y por tener un régimen demográfico más bien cerrado. La recuperación del volumen de población indígena en los siglos dieciocho y diecinueve volvió escaso el suelo agrícola disponible, lo que les impidió atraer inmigrantes en gran escala, a pesar del vivo deseo de sus gobiernos (véase cuadro 1). El saldo migratorio peruano fue positivo en la primera mitad de la centuria, y negativo en la segunda, pero en ambos casos con volúmenes modestos. 
Una singularidad del Perú dentro del panorama del continente fue que habiendo figurado dentro del grupo tardío en cuanto al inicio de la transición demográfica, tuvo luego una caída de la natalidad muy acelerada, habiendo pasado de ser el cuarto país en natalidad elevada en los años 1960-1965, a situarse como el octavo en 19801985 y como el duodécimo en 2000-2005².

Donde se ha presentado, la transición demográfica ha conllevado un fuerte aumento de la población (la así llamada "explosión demográfica"), por el retraso con que la tasa de natalidad de la población se ajustó a la baja de la mortalidad. El gráfico 1 muestra la evolución de dicha transición para el Perú.

Como ya ha sido destacado por otros autores, un elemento que ha diferenciado el proceso demográfico latinoamericano de la clásica experiencia europea, ha sido la rapidez con que se han desenvuelto sus etapas. En palabras de Juan Julio Wicht (1980: 23): “Lo que Europa logró en 150 años, el Perú lo hizo en 25: reducir la mortalidad de 27 por mil a trece por mil." Este rápido cambio despistó a los agentes de políticas y complicó la adaptación de la organización económica y social de la nación a las tendencias demográficas.

La tendencia dominante en el estudio de la demografía peruana y latinoamericana en general, como dejamos dicho más atrás, ha sido considerarla como dependiente sustancialmente del exterior. El arribo de tecnología médica y sanitaria, primero, así como la de métodos anticonceptivos modernos, después, serían los factores explicativos principales de la evolución de la mortalidad y la natalidad. Aunque aquí no se niega el importante papel cumplido por esa transferencia tecnológica, trataremos de enfocar especialmente los compromisos y asociaciones que se establecieron entre las demandas por población, que se hizo desde la economía (para la cual la población se traduce en las variables de mano de obra y consumo), y por mayores ingresos y comodidades que hizo la población; es decir, la mutua interacción entre las dinámicas demográficas y económicas. Ello significará darle un mayor énfasis a los aspectos de la política y la realidad internas, en comparación al enfoque clásico ${ }^{5}$.

El trabajo de reconstrucción estadística de Bruno Seminario y Arlette Beltrán (1998) nos permite conocer que desde 1900 al año 2000 el valor de lo producido por la economía peruana creció cinco y media veces más rápido que la población, aunque en el último cuarto de siglo la tendencia fue al revés (véase cuadro 2).

Para los años 1960-1965 y 1980-1985, véase Merrick, (1997), p. 169. Para 2000-2005, ver CEPAL (2008), p. 29.

La carencia de información cuantitativa confiable para el período anterior a 1970 nos impide desarrollar algún método econométrico que permita medir separadamente (si es que ello fuera posible) el impacto de los factores externo e interno 
GRÁFICO 1

EVOLUCIÓN DE LA NATALIDAD Y MORTALIDAD EN EL PERÚ DEL SIGLO XX

(por millares de habitantes)

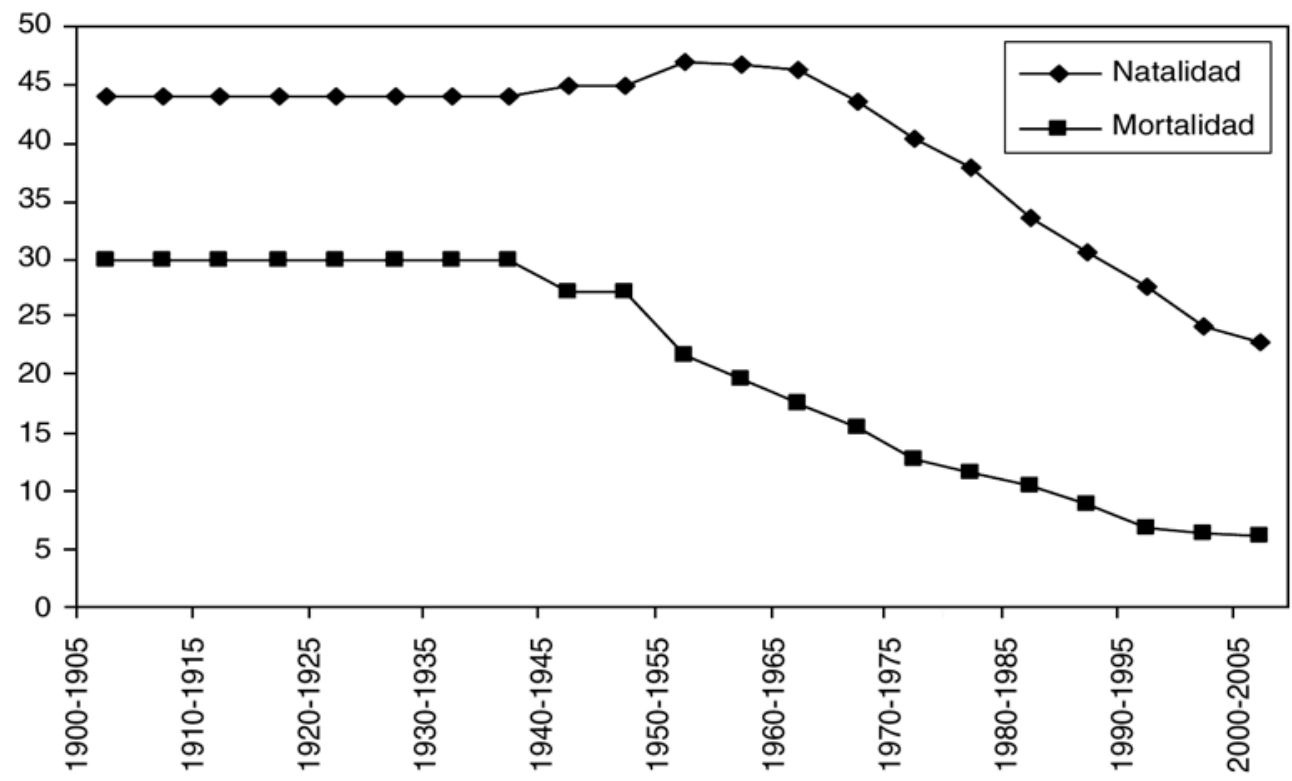

Fuentes: Para los datos de 1900 a 1949: CEPD (1972), aunque la cifra de mortalidad de 1900-1939 debe tomarse solo como aproximada, puesto que esta fuente se limita a indicar 32.5 por mil para el momento del censo de 1876 (pp. 131-132). De 1950 a 1980, INE (1983) y Presidencia del Consejo de Ministros (1993); de 1981 a 1990, INEI (1993); de 1990 en adelante, INEI (1997) (para el quinquenio 1990-1995); INEI (2001) y (2007).

Con todas las reservas que una serie tan larga del PBI puede merecer, el cuadro puede ser útil para evaluar que durante las fases de crecimiento demográfico robusto, la economía también lo hizo a buen ritmo: la fase 1950-1975, por ejemplo; mientras que en las de desaceleración demográfica, como 1975-2000, el crecimiento económico se vio frenado. Las relaciones que se establecen entre el crecimiento económico y el demográfico no han podido ser teorizadas, a pesar de innumerables esfuerzos que se remontan hasta los inicios de la ciencia económica, y parecieran depender de cada caso particular. ${ }^{6}$ Acerquémonos por ello a las situaciones específicas que se fueron dando, revisando las diferentes etapas históricas.

6 En ello coinciden autores como Boserup (1984) y Kuznetz (1974). Para una referencia más reciente, véase Kelley y Schmidt (2001). 
CUADRO 2

EVOLUCIÓN DEL PBI PER CÁPITA EN EL PERÚ DEL SIGLO XX

\begin{tabular}{lcccc}
\hline Períodos & $\begin{array}{c}\text { PBI pc en dólares } \\
\text { de } 1979 \text { en el } \\
\text { año inicial* }\end{array}$ & $\begin{array}{c}\text { PBI pc en dólares } \\
\text { de } 1979 \text { en el } \\
\text { año final }\end{array}$ & $\begin{array}{c}\text { Tasa de crecimiento } \\
\text { porcentual anual del PBI } \\
\text { pc en dólares de 1979 }\end{array}$ & $\begin{array}{c}\text { Tasa de crecimiento } \\
\text { demográfico anual }\end{array}$ \\
\hline $\mathbf{1 9 0 0 - 1 9 3 0}$ & 155 & 381 & 3,05 & 1,37 \\
$\mathbf{1 9 3 0 - 1 9 5 0}$ & 381 & 518 & 1,55 & 1,67 \\
$\mathbf{1 9 5 0 - 1 9 7 5}$ & 518 & 957 & 2,49 & 2,76 \\
$\mathbf{1 9 7 5 - 2 0 0 0}$ & 957 & 850 & $-0,47$ & 2,04 \\
$\mathbf{1 9 0 0 - 2 0 0 0}$ & 155 & 850 & 1,72 & 1,98 \\
\hline
\end{tabular}

Fuentes: Seminario-Beltrán 1998: 255-258; salvo el año 2000, para el que tomé BCRP (2004).

\section{El país rico y vacío: 1900-1930}

Durante el período que corrió desde los años finales del siglo diecinueve, hasta 1930, predominó en el Perú la percepción de ser un país sub poblado en relación a sus posibilidades productivas y a sus necesidades de mano de obra ${ }^{7}$. Dicha percepción derivaba de las dificultades que encaraban los empresarios hacia 1900 para encontrar trabajadores. La reconstrucción de la economía peruana en las décadas que sucedieron a la derrota en la guerra del salitre (1879-1883) consistió en el relanzamiento de una economía de exportación agrícola y minera que, apenas en sus primeros brotes, topó con la rigidez de un mercado laboral de antiguo régimen.

Este fue un hueso duro de roer, ya que los potenciales trabajadores carecían de una sensibilidad por el salario que los empujara a especializarse vendiendo su trabajo a los empresarios. Los requerimientos de las empresas en los sectores minero y agrario que se proponían producir para la exportación no superaban los cincuenta mil o sesenta mil obreros, por lo menos para la primera etapa, de lanzamiento de las empresas. Teniendo el país una población de tres y medio millones de habitantes en 1900, podría sorprender que se percibiese una falta de trabajadores; pero ella era la queja universal de la clase empresarial, al punto que la figura retórica más usual en

7 "[...] queda siempre sentado que la población del Perú es insignificante dada la extensión de su territorio." escribieron, por ejemplo, Chocano, Zuleta y Vidal (1925), para una fecha ya tardía como 1925 (p. 217). 
la prensa de la época, era la de comparar al Perú con la estatua de la Venus de Milo: un cuerpo hermoso, pero sin brazos. La hermosura eran los recursos naturales exuberantes, los brazos faltantes la carencia de operarios para arrancar las riquezas del suelo $^{8}$.

La escasez de mano de obra en el país, era un problema crónico arrastrado desde la temprana época colonial, cuando hubo que traer trabajadores del África para la agricultura, y obligar a la población autóctona sobreviviente a la crisis demográfica de la Conquista, a trabajar en las minas y obrajes de los colonizadores españoles. Incluso en los mediados del siglo diecinueve, la explotación de las islas guaneras y la construcción de las vías férreas requirieron de nuevas importaciones de mano de obra, que esta vez provinieron del continente asiático y las islas de la Polinesia.

La falta de mano de obra para las empresas extractivas podía resolverse a la manera de las metrópolis, o a la manera de las colonias. En el primer caso, el método consistía en terminar con la autonomía de los pequeños productores rurales, despojándolos de sus tierras y pastos, hasta que no tuviesen más medio de subsistencia que la venta de su trabajo a la clase empresarial. Este procedimiento, que en el siglo diecinueve fue bautizado como la "proletarización", enfrentaba, desde luego, enormes dificultades políticas (los pequeños productores podían resistirse a perder sus medios económicos de vida, rebelándose contra el poder económico y su andamiaje legal), pero se facilitaba cuando existía un excedente demográfico en el campo, que empujaba a los pequeños productores a emigrar a las ciudades y otros centros de demanda de trabajadores.

Los métodos coloniales eran propios de países donde la presión demográfica sobre la tierra aún no existía. Entonces se procedía a trasladar mano de obra desde otras partes del mundo, ya fuese en condición de esclavitud, o de trabajadores sujetos a un contrato salarial. Una alternativa dentro de los métodos coloniales era obligar a los pequeños productores, que por lo común pertenecían a la raza conquistada y sometida social y políticamente, a tributar por la tierra de que disponían, en forma de prestaciones de trabajo para los colonos empresarios.

En el Perú la cuestión laboral se resolvió a la manera de las colonias. La crisis demográfica del siglo XVI dejó una relación hombre/tierra tal, que durante un arco

8 En su Reseña industrial del Perú de 1905, un libro promovido por el gobierno para atraer el interés de los inversionistas hacia el país, Alejandro Garland, se refirió al “[...] eterno problema de brazos para la agricultura; [...]" (p. 47). El Ministro de Fomento en 1911, Julio Ego Aguirre (1911) manifestó su preocupación por "Las reiteradas reclamaciones formuladas por la falta de braceros para la explotación minera [...]". Al año siguiente el nuevo Ministro expuso que "El laboreo de las minas ha pasado este año por una verdadera crisis; la falta de operarios por un lado y el incumplimiento de sus compromisos por parte de estos, más generalizado que de ordinario, por otra parte, han impuesto la necesidad de contemplar el problema de un modo serio." García (1912). Véase también Marie (1905) y Rodríguez Dulanto (1907). 
temporal de varios siglos resultó muy difícil estimular la proletarización entre los indígenas. La importación era, por su parte, un método laboral costoso. Debía pagarse los servicios del agente contratista en el país de origen y el viaje del trabajador desde miles de kilómetros de distancia; asumir luego los riesgos de que este enfermase o incluso muriese, a raíz del viaje o de los cambios climáticos, de dieta y medio ambientales. Por último, el trabajador también podía escapar y dejar la inversión perdida. La última importación grande de trabajadores en el Perú, fue la realizada con los japoneses, desde 1898 hasta aproximadamente 1920, quienes fueron destinados principalmente a la agricultura del algodón en la costa9 .

Desde los últimos años del siglo diecinueve el Perú participó del vigoroso auge exportador que caracterizó a América Latina hasta la crisis mundial de 1929, sobrellevando, a veces con elevados costos, las fallas en la oferta laboral. La región de la costa, en cuyos oasis se ubicaba la agricultura de exportación, estaba poco poblada, mientras la de la sierra se caracterizaba por un régimen agrario que no estimulaba la movilidad definitiva o de largo plazo de la población.

Los empresarios recurrieron a soluciones laborales de diverso tipo. Las más frecuentes, aparte de la ya mencionada importación de mano de obra, fueron el "enganche" estacional de campesinos, que permitía el concurso laboral de los pequeños productores agropecuarios independientes durante los meses en que su economía de subsistencia no los demandaba mayormente, y el asentamiento de un sistema de colonato o "yanaconaje", que insertaba un régimen de economía campesina dentro de las haciendas y plantaciones dedicadas a los cultivos de exportación.

El método del enganche fue practicado tanto entre las empresas mineras de la sierra, que así pudieron articularse con la economía campesina de sus entornos regionales, cuanto en las haciendas de la costa, que de esta manera conseguían mano de obra adicional para operaciones puntuales, como la cosecha de algodón o el corte de la caña de azúcar, que no se realizaban a lo largo de todo el año. El sistema consistía en que el empresario contrataba a un agente enganchador para que reclutase campesinos en la región más próxima, que se comprometiesen a trabajar en el centro minero o la hacienda por un número de semanas o de meses. Para mejor persuadir al campesino era común adelantarle parte del salario o hacerle algún obsequio. Solía firmarse un convenio entre el hacendado y el enganchador, y entre éste y el campesino, pero los acuerdos podían ser a veces sólo verbales ${ }^{10}$.

9 Aunque la importación apoyada por el Estado peruano, terminó alrededor de esta fecha, los trabajadores japoneses siguieron llegando, aunque en cifras cada vez menores, hasta los años treinta.

10 Ver sobre el enganche en la minería, Dewind (1977), Bonilla (1974) Contreras (1988) y Long y Roberts (2001); sobre las haciendas y el mundo agrario: González (1985) y Rodríguez Doig (1986). 
El sistema del yanaconaje fue empleado cuando la demanda de trabajo tenía un ritmo más bien constante a lo largo del año, de modo que la estrategia del enganche estacional no era suficiente. Era el caso de las haciendas algodoneras en la costa central, y de las lecheras en la sierra norte. Bajo este método el empresario terrateniente debía ceder parte de sus tierras a los yanaconas, como contra prestación a la obligación de éstos de trabajar en las tierras de la hacienda dedicadas al cultivo de exportación. El terrateniente procuraba, y a veces lo conseguía, que los yanaconas también sembrasen el cultivo de exportación en sus propias parcelas, y le vendiesen la cosecha a un precio ventajoso ${ }^{11}$.

Estas soluciones laborales no eran óptimas desde el punto de vista de los empresarios, puesto que acarreaban elevados riesgos y fuertes costos. Al no existir la amenaza del despido fue difícil introducir la disciplina industrial moderna entre los trabajadores ${ }^{12}$. Además, la inestabilidad de los trabajadores en el centro de labor significaba que constantemente había que adiestrarlos en sus tareas, y que no pudiesen implantarse procedimientos técnicos avanzados (el analfabetismo en el Perú de inicios del siglo veinte rondaba el $80 \%$, pero en el campo era casi absoluto).

El cuadro 3 muestra la evolución de algunos salarios reales en la agricultura de exportación de la costa y en la minería "moderna" (la única que pagaba salarios) entre 1900 y 1940, según la investigación de Shane Hunt. Hubo muchos años sin información de modo que la calidad de esta varía según los sectores. Las cifras dejan ver que los salarios reales subieron hasta la coyuntura de la Primera Guerra Mundial, tendiendo a la baja después, para finalmente recuperarse en los años treinta.

Sin embargo, debe advertirse que incluso en la agricultura y minería de exportación, el salario monetario fue solo uno de los ingredientes de la remuneración. Otros eran la entrega de parcelas de cultivo (especialmente en el caso del algodón), víveres, bebidas y ayudas ocasionales (a veces monetarias) del patrón, que podían llegar a ser tan importantes como el salario ${ }^{13}$. Aun así, la economía campesina de subsistencia cubría un conjunto de necesidades vitales y sociales, que la remuneración del patrón en la mina o la plantación no alcanzaba a satisfacer, lo que explicaría la renuencia de los campesinos a inscribirse en la economía asalariada. En cualquier caso, los empresarios sabían que mientras no hubiese una presión demográfica sobre la tierra que expulsase gente del campo y la empujase a buscar trabajo dependiente, persistirían los altos costos laborales o las fórmulas laborales ineficientes desde el

Ver Peloso (1999), para el caso de las haciendas algodoneras, y Deere (1992), para el caso de las lecheras. Las quejas de los empresarios por la poca disposición al trabajo de los operarios eran constantes. Por ejemplo, aunque teóricamente la semana laboral corría desde el lunes por la mañana hasta el sábado al mediodía, en la práctica la semana no comenzaba hasta la mañana del miércoles; el alcoholismo y las riñas en el trabajo eran pan de cada día. Véase Contreras (1988). 


\section{CUADRO 3}

EVOLUCIÓN DE LOS SALARIOS REALES EN LA AGRICULTURA DE LA COSTA

Y LA MINERÍA PERUANAS (OBREROS), 1895-1940

$(1924=100)$

\begin{tabular}{lcccc}
\hline Años & $\begin{array}{c}\text { Campos } \\
\text { azucareros }\end{array}$ & $\begin{array}{c}\text { Campos } \\
\text { algodoneros }\end{array}$ & Minería & $\begin{array}{c}\text { Total industrias } \\
\text { extractivas }\end{array}$ \\
\hline $\mathbf{1 8 9 5}$ & 111 & & 87 & \\
$\mathbf{1 9 0 7}$ & 126 & & 105 & \\
$\mathbf{1 9 1 2}$ & 139 & & 100 & \\
$\mathbf{1 9 1 3}$ & 135 & & 102 & \\
$\mathbf{1 9 1 6}$ & 105 & 75 & 91 & \\
$\mathbf{1 9 1 9}$ & 107 & 92 & 113 & 109 \\
$\mathbf{1 9 2 5}$ & 93 & & & 187 \\
$\mathbf{1 9 2 8}$ & 98 & & & 126 \\
$\mathbf{1 9 3 2}$ & 101 & 67 & & 121 \\
$\mathbf{1 9 3 6}$ & 114 & 88 & & \\
$\mathbf{1 9 4 0}$ & 109 & 73 & & \\
\hline
\end{tabular}

Fuentes: Shane Hunt (1980), pp. 120-121.

punto de vista de su economía. Esta constatación fue una de las presiones que hubo en el Perú hasta los años treinta, para que el Estado adoptase una política expansiva de población. Esta debía tanto "fomentar el crecimiento natural de la población indígena [...] raza que constituye el núcleo de nuestra población, y es por lo mismo factor necesario y valiosísimo para el aprovechamiento de nuestras riquezas naturales." (Garland 1905; pp. 47/48), cuanto procurar la llegada de inmigrantes ${ }^{14}$.

Tras constatar que la tasa de natalidad del país se ubicaba entre las más altas de América, para conseguir el aumento de la población el Estado puso empeño en procurar la reducción de la mortalidad, especialmente de la infantil. El control de las plagas y enfermedades era visto, además, como una medida que colaboraba con la política inmigratoria, puesto que uno de los obstáculos con que topaban los agentes del gobierno peruano en las principales ciudades europeas para su campaña por atraer familias al Perú, eran las noticias acerca de la proliferación de epidemias y la elevada mortalidad infantil en él. Brigadas de sanitarios y obstétricas llevando vacu-

14 Acerca de la inmigración surgió un debate acerca de la conveniencia de la inmigración asiática o europea. Ver nuestro trabajo (2004), cap. 6. 
nas y cartillas para el control de la atención de los recién nacidos, fueron echadas al campo con el propósito de reducir la mortalidad al nivel de los países más avanzados, ya que no del mundo, al menos de Sudamérica. En 1903 fue creada la Dirección Nacional de Salubridad, centralizándose una función pública que hasta entonces había estado confiada a las municipalidades y las sociedades locales de beneficencia. El Ministerio de Justicia, Instrucción, Beneficencia y Culto, que tenía bajo su cargo a la Dirección de Salubridad vio crecer su participación en el gasto público, de un promedio de $10 \%$ en $1900-1902$, a uno de $16 \%$ en $1916-1918^{15}$.

\section{El fin de la política expansiva}

A partir de los años treinta se advertiría un cambio en la política demográfica, emitiendo el Estado una serie de leyes que pusieron fin a la política pro inmigratoria. Así, en 1932 decretó que no podía haber ningún sector de la economía donde más del $20 \%$ de establecimientos estuviese en manos de extranjeros, a la vez que ningún establecimiento podía tener más del $20 \%$ de su nómina de empleados y obreros ocupada por extranjeros. Lo pagado por sueldos y salarios por una empresa, tampoco podía tener más de un quinto para extranjeros. También se exigió un capital mínimo de dos mil soles para el asentamiento de un inmigrante, se prohibió la entrada de extranjeros en calidad de "colonos", y en 1936 se puso un tope de dieciséis mil personas por nacionalidad como el máximo que el Perú podía albergar de población extranjera. Un registro de la población extranjera del mismo año, estimó en 22,560 el número de japoneses en el Perú, quienes así, habrían excedido ya el número máximo, de modo que no se permitiría el ingreso de más japoneses ${ }^{16}$.

La crisis mundial de 1929 provocó el derrumbe de las exportaciones peruanas, puesto que los precios de las materias primas, pero sobre todo de las mineras, cayeron en los años siguientes. La contracción del comercio exterior significó el desempleo de miles de trabajadores, sobre todo en sectores como la minería, cuya producción se destinaba casi enteramente al mercado exterior, y en el comercio urbano que trabajaba sobre la base de bienes importados. El piso se tocó en 1932, pero los niveles de finales de los años veinte no se recuperaron en algunos casos sino hasta después de la Segunda Guerra Mundial (véase cuadro 4).

15 Portocarrero, Beltrán y Romero (1992), p. 111.

16 Datos tomados de Giovanni Bonfiglio (2001) pp. 73-81. Bonfiglio señala que buena parte de la legislación mencionada apuntó específicamente contra la inmigración japonesa. 
CUADRO 4

EVOLUCIÓN DEL NÚMERO DE TRABAJADORES EN EL PERÚ EN RENGLONES ECONÓMICOS DE EXPORTACIÓN, ANTES Y DESPUÉS DE LA CRISIS DE 1929

\begin{tabular}{lrrrrr}
\hline \multicolumn{1}{c}{ Ramo } & Año 1924 & Año 1928 & Año 1932 & Año 1936 & Año 1940 \\
\hline Caña de azúcar & 25.561 & 25.732 & 20.506 & 20.454 & 23.444 \\
Elaboración de azúcar & 4.490 & 4.419 & 4.054 & 4.006 & 4.314 \\
Algodón & $40.557^{\star}$ & n.d. & 40.360 & 105.457 & 117.726 \\
Minería (obreros) & 20.238 & 25.430 & 13.004 & 29.428 & 35.486 \\
Minería (empleados) & 2.420 & 3.045 & 1.193 & 1.589 & 2.186 \\
Valor de las exportaciones & & & & & \\
(en millones de dólares corrientes) & 101,7 & 125,1 & 38,1 & 83,5 & 65,8 \\
\hline
\end{tabular}

* Corresponde a 1923

Fuentes: Ministerio de Hacienda, 1947; pp. 344-345 y 450-458

Hubo casos en que los trabajadores despedidos pudieron volver a su economía agraria de origen, pero otros habrían cortado ya sus vínculos con la sociedad agraria de procedencia que hubiesen permitido una reinserción.

La región de la sierra, que reunía por esos años a dos tercios de la población del país, comenzaba a mostrar signos claros de un agotamiento del factor tierra ${ }^{17}$. Tal es el contexto en el que hay que entender el cambio en la política migratoria del Estado peruano. Uno de escasez de recursos, desempleo y contracción en la actividad económica. La situación de abundancia de tierra con la que el país había vivido cuatrocientos años llegaba a su fin. En los años treinta el Perú alcanzó los seis millones de habitantes, que habría sido su volumen de población antes de la conquista española. El largo proceso de "recuperación demográfica" había, así, terminado. En esta década fue que se dejaron oír las primeras voces que criticaron abiertamente la idea del Perú como un país rico en recursos pero escaso de hombres:

17 “[...] en la Sierra la regla general es una gran división de la propiedad, que llega a extremos como en el valle de Chupaca donde el tamaño promedio es de 2 yugadas (2/3 de ha.) en el lado derecho y de 5 a 6 yugadas (1.5 a 2 has.) en el lazo izquierdo [...].", señalaba en 1938, un observador que fue más tarde Ministro de Hacienda. Ferrero (1938), p. 26. 
“Contrariamente a lo que se cree, el Perú es un país muy pobre en tierras de cultivo, pues su inmensa extensión territorial es en su mayor parte, inadaptable a la explotación agrícola. Y resulta curioso constatar, sin embargo, con cuánta frecuencia se escribe y se habla sobre la necesidad de poblar el territorio y de favorecer corrientes de inmigración"18.

Con estas palabras sacudía a su auditorio del Círculo Militar del Perú, el abogado y economista Raúl Ferrero, en una conferencia pronunciada en 1940, acerca de la “Integración económica del Perú y la defensa de sus riquezas"19. Ferrero apeló en dicha oportunidad al concepto de "población relativa", que tomaba en cuenta el volumen demográfico de un país en relación a su disponibilidad de tierras útiles, o de cultivo. Con apenas un millón y medio de hectáreas cultivadas, que no equivalían más que al 1.2\% de toda la extensión territorial nacional, la realidad del Perú era que "nuestra población relativa es sumamente elevada, pues llega a 420 habitantes por kilómetro cuadrado" (de tierra cultivada) ${ }^{20}$. En un ejercicio comparativo con otros países latinoamericanos, el Perú, a pesar de su menor densidad en términos "absolutos" (habitantes por kilómetro cuadrado de territorio), quedaba peor situado en términos relativos.

Diversos signos indicaban que la era de la escasez de trabajadores en el Perú había llegado a su fin. El hecho de que en 1930 pudiera, por ejemplo, abolirse la Ley de Conscripción Vial creada por Leguía diez años atrás, para proveer de mano de obra a la construcción de carreteras, y que a pesar de ello siguieran construyéndose carreteras y ferrocarriles en los años treinta, prueba que, incluso en el interior del Perú, ya no digamos en las ciudades, se había formado un mercado laboral. ${ }^{21} \mathrm{El}$ otro signo fue la extinción del enganche como mecanismo de reclutamiento laboral. El momento varió según las regiones, pero entre las décadas de 1930 y 1950 fue desapareciendo esta práctica en el país. Dejó de ser necesaria puesto que ante la falta de tierras y agua y el aumento de sus necesidades monetarias, los campesinos se presentaban ya espontáneamente ante los empleadores en búsqueda de empleo ${ }^{22}$.

La presión demográfica en la sierra era tal, que incluso la andenería abandonada durante siglos, comenzaba a ser rehabilitada y cultivada nuevamente. En lugares como el Cuzco y Arequipa: se “[...] tienen que aprovechar hasta lotes pequeños de

\footnotetext{
18 Ferrero (1984-1993 [1941]), p. 230.

19 En el mismo sentido se puede citar el trabajo de Ferrero, "Tierra y población en el Perú", de 1938.

$20 \quad$ Ferrero (1984-1993 [1941]), p. 231.

21 El proceso fue, sin duda, paulatino. Gerbi (1941), p. 378, sostenía, por ejemplo, a fines de los años treinta, que cuando se emprendían obras viales en el país, esto se hacía "[...] absorbiendo toda la mano de obra indispensable en el lugar, creando a menudo dificultades a las haciendas y minas, [...]." Pero quizás lo decía interesadamente, para justificar su entusiasmo por la inmigración.

22 Las referencias sobre el fin del enganche pueden ser recogidas en los trabajos de Deere (1992), Thorp-Bertram 1985, Salazar-Soler (2006) y Long y Roberts (2001).
} 
tierras materialmente suspendidos en las alturas, con rendimientos mediocres" ${ }^{\prime 23}$. $\mathrm{Si}$ se habilitasen nuevas tierras de cultivo para recibir a los inmigrantes, rápidamente éstas serían ocupadas por la población local excedente. "[...] a estos millones de seres autóctonos no se les puede hacer desaparecer directa ni indirectamente, lo que de ser posible entrañaría una tremenda injusticia, [...]", reflexionaba González.

Quienes, como Ferrero y González, orientaban o dirigían la política de la época, pensaban que el Perú había caído en una trampa demográfica: la población no podía crecer por falta de tierras, al tiempo que la carencia de una suficiente densidad demográfica, como de riqueza, impedían el tránsito de una economía agrícola pastoril a un estadio más evolucionado, de tipo industrial ${ }^{24}$. No era fácil habilitar más tierras de cultivo, por la falta de agua. Trazar una política de población en el Perú de los años cuarenta, resultaba así una cuestión complicada. Si considerábamos las tierras y los recursos disponibles, ya éramos muchos; pero si queríamos pasar de la economía agrícola a la manufacturera, resultaba que éramos muy pocos y, encima, inadecuados (pobres y con poco apetito de consumo). Nuevamente así se ponía sobre el tapete la cuestión de la "autogenia"; siendo de los ocho millones de habitantes de 1950, tres millones de raza blanca y mestiza, y cinco de la autóctona: "Es indudable -sentenciaba González (1952: 43) — que el país posee en la raza indígena desde el punto de vista de ganarla para la producción y consumo, el problema más serio por resolver. Problema hasta ahora planteado con sentido teórico y literario,...". Auto genista por resignación, el ingeniero agrónomo postulaba que debía procederse a "la culturización" del indio, como un camino para su integración nacional y su cruce con otras razas ${ }^{25}$. La educación del indio, por su parte, haría disminuir su elevado crecimiento demográfico.

La cruzada educativa y sanitaria (que incorporaba fuertes dosis de educación en materia de nutrición, "higiene y urbanidad") en la que se empeñó el Estado peruano a lo largo del siglo veinte, persiguió esa "enorme y conveniente tarea", como la llamó González. Para ilustrar este impulso con una cifra, podemos señalar que entre 1940 y 1961, la tasa de escolaridad de la población de seis a catorce años en el Perú, casi se duplicó, al pasar del 30 al 58\%. En el grupo de quince a diecinueve años, la

23 González (1952), p. 39. González había sido Ministro de Agricultura en la década anterior.

24 “[... nuestra población es de muy bajo poder adquisitivo, no constituye un buen mercado interno que pueda consumir los productos de la futura industria nacional. De ahí que nuestras industrias lleven una vida lánguida y, a veces, hasta precaria. Resulta ingenuo hablar del establecimiento de grandes industrias en un país que no cuenta con una población numerosa ni rica. Igualmente, la escasez de tierras, que se traduce en falta de medios de alimentación, retarda nuestro crecimiento demográfico porque constituye una limitación al desarrollo vegetativo, y, además, porque no alienta la inmigración." Ferrero (1984-1993 [1941]), p. 236.

25 La "autogenia" fue un término acuñado en 1908 por Francisco Graña. Era la versión nacional de la "eugenesia", proponiendo el mejoramiento de la raza nativa como solución al problema nacional. 
tendencia fue similar, ya que creció del 17 al 33\%. Para 1981 las tasas fueron de 90 y $57 \%$ respectivamente ${ }^{26}$.

Superada la crisis de los años treinta, la economía peruana retomó su estilo de crecimiento basado en la exportación de recursos naturales a los mercados mundiales. Así, a lo largo de la primera mitad del siglo veinte el crecimiento del sector capitalista de la economía -es decir, de la producción agrícola y minera para la exportación, de la industria urbana y de las provincias de Lima y Callao en general一, permitió absorber la oferta de trabajo creada por el crecimiento demográfico. Según los estudios de Shane Hunt (1980: 113), entre 1908 y 1940 el empleo en este sector subió de 158,176 a 432,220 trabajadores; es decir, a una tasa de 3.2\% al año, que era superior a la del crecimiento demográfico. Pero debe tomarse en cuenta que la población que salía anualmente al mercado de trabajo no se hallaba determinada solamente por el incremento demográfico, sino que acrecía con la población que se trasladaba del sector de auto subsistencia al capitalista. Este traslado era impulsado por la propia cruzada educativa y de construcción de carreteras que había lanzado el gobier$\mathrm{no}^{27}$.

El apetito por mano de obra entre las empresas modernas permitió una importante mejora en las condiciones laborales. En los años treinta, y en parte por la presión política del partido aprista y el comunista, se inició la legislación laboral que sancionaba el reconocimiento de los accidentes de trabajo, la compensación por tiempo de servicios, las vacaciones y los días feriados pagados, así como el seguro social de maternidad, enfermedad y vejez para los obreros. Estas mejoras se limitaron a la capital de la república, y algunos departamentos como Junín, Piura, Ica, La Libertad y Lambayeque, donde operaban las empresas modernas de la economía de exportación. En el resto del Perú (que comprendía unos quince departamentos más), el régimen salarial era aún desconocido ${ }^{28}$.

Un cuarto de siglo más tarde se había añadido a este paquete, el pago del salario dominical (1948), la participación en las utilidades (1951), el Fondo de Salud y Bienestar Social (1951), la jubilación de los obreros (que en verdad venía a ser una ampliación del seguro de vejez antes existente) y la duplicación de los beneficios de las vacaciones y la compensación, que, así, prácticamente se igualaron con el régimen de los "empleados" 29 . Para estos se creó, además, una bonificación del 30\% al

Francke (1986), p. 304.

El ingeniero González (1952), p. 44, señaló por esos años que debía preverse que la "culturización" del indio que él recomendaba, lo alejaría de las ocupaciones, como la agricultura, que entonces practicaba. Ferrero (1984-1993 [1941]), vol. IV, pp. 239-240.

Hasta los años de 1970 existió en el Perú una división entre el personal "obrero" (que hacían trabajo manual) y el de "empleados" (que hacían trabajo de oficina), teniendo cada uno de estos estamentos su propia legislación laboral, así como sus propios hospitales y sistemas de salud. 
cumplir los treinta años de servicio en una misma empresa, la jubilación con sueldo íntegro tras cuarenta años de servicios (después, rebajados a treinta y cinco), el seguro de enfermedad y maternidad, y el de vejez y pago de una pensión a los sobrevivientes. Igual que para los obreros, a los empleados también se les concedió participación en las utilidades y el Fondo de Salud y Bienestar Social ${ }^{30}$.

Estos beneficios laborales concedidos a lo largo de las décadas de 1930 a 1950 sirvieron para terminar de fijar a la población trabajadora en su nuevo estatus y disuadirlos de retornar a su economía de refugio en el campo. Terminada la vida útil del trabajador, el Estado se comprometía a sostenerlo en la vejez y en los períodos de enfermedad, así como en las ocasiones del nacimiento de su prole. Un miembro de la elite social y política del país, como Rómulo Ferrero (1963: 14) se quejaba, sin embargo, de los costos que ello traía para los empresarios: si en 1939 los beneficios laborales sumaban el $24.2 \%$ del salario básico del obrero y el $21.9 \%$ del empleado, para 1962 habían subido al 60.4\% y 50.6\% respectivamente, encareciendo la creación de puestos de trabajo.

La extensión de tierras de cultivo creció sólo lentamente en los mediados del siglo XX: en el lapso de más de tres décadas que corrieron de 1929 a 1961, aumentó 27\%: de 1.464,000 has. a 1.856,000 has. Después mejoró un poco el ritmo, pero aun así, hasta 1971 el incremento acumulado era sólo del 50\% respecto del área disponible en 1929. A su lado, la población, entre las mismas fechas había crecido en $150 \%$ aproximadamente (ver cuadro 5). Ello explica la crisis de la economía serrana en los mediados del siglo XX y la masiva migración sierra-costa y campo-ciudad que comenzó entonces a generarse. Las regiones de la sierra y selva habían sido las menos dinámicas en el incremento de área cultivada, puesto que de 1929 a 1971 sólo crecieron en $40 \%$ (mientras que en la costa el crecimiento fue de $79 \%)^{31}$. El cuadro 6 muestra la evolución de la distribución demográfica por grandes regiones del Perú, según los censos de 1876 al 2005.

Desde 1940 la región de la sierra redujo su peso demográfico en el país: de haber representado casi dos tercios del total, disminuyó a poco menos de un tercio en el censo de 1993. No solamente no se amplió el área cultivada en la región, sino que tampoco hubo en ella ganancias en la productividad que se arrancaba del suelo, salvo en la minería. Rómulo Ferrero, en su ya citado artículo de 1938, la calificó como una "[...] economía local, de ciclo cerrado y primitivo, [...]" (p. 234). El arcaísmo de las costumbres y la baja tecnología hicieron que, tanto él como otros testigos, consideraran que la organización económica y social de la región significaba una rémora para el país.

\footnotetext{
$30 \quad$ Rómulo Ferrero (1963), p. 14.

31 Thorp y Bertram (1985), p. 424.
} 
CUADRO 5

EVOLUCIÓN DEL ÁREA CULTIVADA EN EL PERÚ, 1929-2004

\begin{tabular}{lccc}
\hline Años & $\begin{array}{c}\text { Superficie cultivada } \\
\text { (Miles de Has.) }\end{array}$ & $\begin{array}{c}\text { Población total } \\
\text { (en millones de habitantes) }\end{array}$ & $\begin{array}{c}\text { Relación Has. cultivadas } \\
\text { por habitante }\end{array}$ \\
\hline $\mathbf{1 9 2 9}$ & 1464 & 5,4 & 0,27 \\
$\mathbf{1 9 4 3}$ & 1486 & 6,8 & 0,22 \\
$\mathbf{1 9 5 2}$ & 1676 & 8,0 & 0,21 \\
$\mathbf{1 9 6 1}$ & 1856 & 10,2 & 0,18 \\
$\mathbf{1 9 6 7}$ & 2042 & 12,1 & 0,17 \\
$\mathbf{1 9 7 1}$ & 2194 & 13,5 & 0,17 \\
$\mathbf{1 9 8 0}$ & 2283 & 17,3 & 0,13 \\
$\mathbf{1 9 8 4}$ & 2601 & 19,2 & 0,14 \\
$\mathbf{2 0 0 0}$ & 2755 & 25,6 & 0,11 \\
$\mathbf{2 0 0 5}$ & 2816 & 27,1 & 0,10 \\
\hline
\end{tabular}

Fuentes: Para el dato de la superficie, para el período 1929-1971: Thorp-Bertram 1985: 424; para 1980-1984: Ministerio de Agricultura 1990; para el período 2000-2005, INEI 2006, p. 461. La relación has. cultivadas por habitante se ha obtenido usando los datos de población de Seminario-Beltrán 1998: 155-157.

CUADRO 6

DISTRIBUCIÓN DEMOGRÁFICA PERUANA EN LAS TRES REGIONES NATURALES SEGÚN LOS CENSOS DE 1876-2005

\begin{tabular}{|c|c|c|c|c|c|c|}
\hline \multirow[t]{2}{*}{ Censo de } & \multicolumn{2}{|c|}{ Costa* $^{*}$} & \multicolumn{2}{|c|}{ Sierra* } & \multicolumn{2}{|c|}{ Selva* } \\
\hline & Población & $\%$ & Población & $\%$ & Población & $\%$ \\
\hline 1876 & 612.168 & 22,68 & 1.866 .274 & 69,14 & 220.818 & 8,18 \\
\hline 1940 & 1.791 .224 & 28,85 & 4.002 .381 & 64,47 & 414.362 & 6,67 \\
\hline 1961 & 3.915 .387 & 39,52 & 5.128 .282 & 51,77 & 863.077 & 8,71 \\
\hline 1972 & 6.140 .481 & 45,36 & 5.849 .338 & 43,21 & 1.548 .389 & 11,44 \\
\hline 1981 & 8.597 .266 & 50,56 & 6.370 .067 & 37,46 & 2.037 .877 & 11,98 \\
\hline 1993 & 11.746 .037 & 53,27 & 7.260 .929 & 32,93 & 3.041 .390 & 13,79 \\
\hline 2005 & 14.136 .301 & 54,05 & 8.435 .006 & 32,25 & 3.580 .958 & 13,70 \\
\hline
\end{tabular}

* Para la distribución de la población entre las tres regiones, asignamos a la región de la Costa a las provincias cuya capital estuviese por debajo de los dos mil metros snm, hacia el lado del Océano Pacífico; para la región de la Selva el criterio fue el mismo, pero para el lado del Atlántico. Por encima de los dos mil metros snm, se consideró Sierra.

Fuentes: Censos nacionales citados. Para el caso de 1876, el dato es de Hunt 1980: 104, quien trabajó con la población censada más la omitida (lo que infló la cifra para la Selva). En los demás, es sólo población censada. 
Sin una ampliación del área aprovechable para la agricultura y la ganadería, penetrada por carreteras que rompieron su tradicional autarquía y asediada por nuevas ideas políticas que cuestionaron el "antiguo régimen" social imperante, la creciente población serrana comenzó, desde la década de 1940, a ser protagonista de rebeliones campesinas que demandaban un reparto más equitativo de la tierra y una mayor atención a sus condiciones de vida. El régimen social agrario de la sierra se había formado en la época colonial, y consistía en la coexistencia de dos unidades sociales, que eran la comunidad indígena y la hacienda española. Tanto la una como la otra cultivaban solamente una fracción de sus tierras, reservando la mayor parte para pastos, forraje y combustible. La rotación en el uso de las tierras para estos distintos propósitos, era otro elemento importante en su tipo de economía. Este régimen se formó en una época de abundancia de tierras y poca densidad demográfica. Cuando ésta aumentó no pudo ser más mantenido. La crisis de la sociedad agraria serrana tuvo que ver con la incapacidad de la hacienda y la comunidad campesina para absorber una mayor población ${ }^{32}$. La transferencia de las tierras de las haciendas a las comunidades llevada a cabo por las reformas agrarias de 1962 y 1969, no representaría una solución a la crisis, puesto que la escasez de tierras afectaba también a las mismas haciendas. La emigración hacia la costa, primero, y hacia la selva, después, fue una forma de aliviar la presión social en la convulsionada región serrana ${ }^{33}$.

Hacia 1950 el ingeniero González (1952: 43) había previsto que la economía de la costa debía especializarse en los cultivos de exportación, mientras la de la sierra debía abastecer de alimentos a la población de la costa, aparte de sí misma. Pero para que este plan funcionase la agricultura serrana debía mejorar su productividad, lo que no sucedió. Lo que aumentó fue su población, pero sin que se produjera el "population push" de Ester Boserup ${ }^{34}$.

Desde mediados de siglo la velocidad de crecimiento del empleo en el sector moderno de la economía menguó. Los sectores de exportación, en parte como reacción al encarecimiento del trabajo, recurrieron a fórmulas de producción más tecnificadas, que reemplazaron la mano de obra por el capital. Siguiendo los cálculos de Shane Hunt y Richard Webb, la masa laboral en el sector considerado moderno, o

32 Sobre ello, ver Cotlear (1989), Deere (1992) y Caballero (1981).

33 Según Seth Norton (2002) la falta de definición de derechos de propiedad privados, promueve la fertilidad en las sociedades, puesto que en un marco de deficiente definición y defensa de dichos derechos, un mayor tamaño de la familia ayuda a obtener los recursos de tierra, agua, combustible, etc. Sobre ello ver también Debraj Ray (2002), pp. 299 y ss. En este sentido, la sociedad tradicional andina tuvo un sistema de propiedad de tipo colectivista sobre los recursos agrarios, que habría favorecido el patrón de alta natalidad.

34 En ello hubo también una falla del marco institucional. En vez de dictar medidas que facilitaran el cambio tecnológico, los gobiernos volvieron más rígido el marco laboral. La ley de yanaconaje de 1947 (en ciernes desde 1932, cuando su proyecto fue ya lanzado por Hildebrando Castro Pozo), impidió a los hacendados remover y reorganizar a la población laboral de sus fundos. 
capitalista, de la economía, creció entre 1950 y 1961, de 458 mil a 603 mil, y su peso dentro del total de la población trabajadora, apenas se movió: del 17.7 al 19.9\%. ${ }^{35}$ Dentro de esa población trabajadora moderna los autores incluyeron a los empleados del gobierno, cuyo crecimiento fue el más rápido, por la expansión de la educación y la salud públicas y el crecimiento de las fuerzas armadas. Si considerásemos aisladamente dos sectores "modernos", como la minería y la industria manufacturera, veríamos que de 1940 a 1961, ambas vieron crecer su número de trabajadores más modestamente: de 45 mil a 66 mil en el caso de la minería, y de $380 \mathrm{mil}$ a $411 \mathrm{mil}$, en el de la manufactura; lo que implica tasas de incremento anual de $1.9 \%$ y $0.4 \%$ respectivamente; muy por debajo del crecimiento de la población económicamente activa.

Después de 1940, a diferencia del período anterior, la economía peruana no estaba brindando empleos con la velocidad que le imponía la explosión demográfica en marcha. El único sector nuevo que absorbió un número importante de emigrantes de la sierra, fue el de la pesca, durante los años cincuenta y sesenta ${ }^{36}$. En cierta forma tiene razón, sin embargo, Ester Boserup (1984), cuando señala que el mismo crecimiento de la densidad de la población suele llevar a innovaciones técnicas que, a su vez, conducen a fases más avanzadas del desarrollo económico. Así, el aumento de la población en el Perú en la segunda mitad del siglo veinte, junto con la migración campo-ciudad, estimuló un mejoramiento de la red vial y de las comunicaciones en general. Estas, a su vez, permitirían el incremento del comercio y de la industria de bienes de consumo. El aumento de la población urbana, por su lado, estimuló el sector construcción y la provisión de servicios como el alcantarillado, la electricidad y la telefonía. Desde mediados del siglo veinte, los periódicos y la radio dejaron de ser medios que atendían solamente a una elite. Gracias a las carreteras, el comercio y el avance de la alfabetización, el largo tiempo reclamado mercado interno comenzaba a hacerse presente, al punto que las ideas económicas de la CEPAL, que defendían programas de impulso a la industrialización, empezaron también a ser oídas en el Perú de los años cincuenta y sesenta ${ }^{37}$.

La mala distribución del ingreso (como secuela del tipo de propiedad existente sobre el sector exportador) y la falta de ampliación de la tierra cultivable debilitaron, no obstante, la difusión de un proceso de industrialización que hiciera de las ciudades polos productivos y no únicamente plazas de comercio y administración

Hunt (1940), p. 89, Webb-Figueroa (1975).

La actividad pesquera industrial llegó a absorber unos 38 mil trabajadores, fuera de otros veinte mil ocupados en la fabricación de la harina de pescado. Thorp-Bertram (1985), p. 387.

Es frecuente leer que el Perú fue un país que no se sumó a la ola de industrialización por sustitución de importaciones de América Latina en los años treinta, como lo habrían hecho en cambio, México, Brasil y Argentina; y que el ingreso del Perú a este tipo de planteamiento se dio "tardíamente", en los años sesenta y setenta. Pero es evidente que en los años treinta el Perú carecía de un mercado interno que pudiese sostener un esfuerzo industrialista. 
pública $^{38}$. Desde los años sesenta comenzaron a salir al mercado de trabajo, y sobre todo a las ciudades, los hijos de la "explosión demográfica" iniciada en los años cuarenta, en un torrente que fue cobrando mayor fuerza en las décadas siguientes. Carente la economía de un sector dinámico en materia de empleo, que pudiera absorber este flujo, se generó una estructura dual en la que, al lado de un sector moderno y capitalista, se formó uno más grande, de subsistencia, que lo proveía de trabajadores eventuales e impedía que sus salarios subiesen al compás de las ganancias de los empresarios (véase cuadro 7) ${ }^{39}$. La parte del PBI que correspondía a las remuneraciones de los trabajadores cayó de un promedio de 48 por ciento en la década de 1960, a uno de 37 por ciento en el quinquenio 1984-198840. A partir de los años sesenta éramos una economía poscolonial y superpoblada. Lo primero, porque los sectores de acumulación que eran el asidero del poder económico, consistían en la extracción de materias primas para la exportación; lo segundo, porque ni el sector indígena podía ya albergar a toda su población, ni el sector exportador podía absorber ese excedente demográfico. El excedente indígena emigraba a las ciudades, donde pasó a constituir un conglomerado mendicante, tildado antaño de "marginal" y más recientemente de "informal".

Como una forma de aliviar la presión política generada por el elevado desempleo y subempleo, el aparato estatal salió a brindar trabajo a un ritmo que hizo elevar el número de trabajadores públicos diez veces entre mediados y finales del siglo XX. En 1940 los trabajadores del sector público eran 89 mil, representando el 3.6\% de la fuerza laboral de dicho año; para 1961, ya eran 176 mil (y el 5.8\% de la fuerza laboral); para 1987 llegaron a 773 mil (con el $11.1 \%$ de la fuerza laboral) ${ }^{41}$.

\section{La política represiva en materia de población}

Como en toda América Latina, en el Perú los años setenta marcaron una inflexión en la historia de la población. De un lado, apareció la conciencia de una sobrepoblación nacional, y con ella, dentro del Estado, la preocupación por reprimir la natalidad tra-

38 Según Coale (1978), la mala distribución del ingreso es consecuencia del elevado crecimiento demográfico, en virtud del "comportamiento demográfico diferencial" en la población. Ver Otero, (1997). De modo que incluso si no frena el crecimiento económico, sí dificulta su distribución.

Esta es la estructura que Arthur Lewis (1963) presentó en un estudio ya clásico “El desarrollo económico con oferta ilimitada de trabajo".

40 Datos tomados de Huamán (1989).

41 Hunt (1980), para el dato de 1940; para 1961: Thorp-Bertram (1985), p. 396; para 1987, INE (1988), pp. 11 y 13. Hacia el inicio del 2005, el número de empleados públicos se estimaba, según el Ministro de Economía, Pedro P. Kuczynski, en una cifra de entre 1.2 y 1.3 millones. 


\section{CUADRO 7}

EVOLUCIÓN DE LAS REMUNERACIONES REALES EN EL PERÚ, 1960-1990

\begin{tabular}{lcc}
\hline Años $^{*}$ & $\begin{array}{c}\text { Sueldos** } \\
\text { Índices (1973=100) }\end{array}$ & $\begin{array}{c}\text { Salarios en Lima Metropolitana } \\
\text { En soles de 1979 }\end{array}$ \\
\hline $\mathbf{1 9 6 0}$ & 88,3 & 968 \\
$\mathbf{1 9 6 5}$ & 85,8 & 1.151 \\
$\mathbf{1 9 7 0}$ & 86,1 & 1.174 \\
$\mathbf{1 9 7 5}$ & 89,3 & 1.310 \\
$\mathbf{1 9 8 0}$ & 57,3 & 1.015 \\
$\mathbf{1 9 8 5}$ & 54,2 & 734 \\
$\mathbf{1 9 9 0}$ & & 346 \\
\hline${ }^{*}$ Cada año recibió el valor promediado de tres años \\
** En empresas de diez o más trabajadores, excluyendo el sector agrícola \\
\hline \multicolumn{2}{l}{ Fuentes: Huamán (1989) para Sueldos; Páucar (1997), pp. 71-72 para Salarios en } \\
Lima Metropolitana \\
\hline
\end{tabular}

dicionalmente elevada de las familias, sobre todo en el medio rural. De otro, la natalidad en efecto, comenzó a disminuir, abriendo así paso a una segunda etapa en la transición demográfica. En las ciudades la población disminuyó su fecundidad como respuesta a las restricciones propias de la vida urbana, mientras en el campo el Estado aplicó agresivos programas con la meta de reducir el crecimiento demográfico y la tasa global de fecundidad.

Hacia 1975 los signos de la sobrepoblación eran ya evidentes en el país: el desempleo abierto alcanzó en dicho año el 5\% y el subempleo el 42\%. Para 1984 dichas cifras subieron a 11 y 54 respectivamente ${ }^{42}$. Solo un tercio de la población, ese que pertenecía al sector moderno o capitalista de la economía, estaba "adecuadamente empleado". El desempleo y la pobreza extrema eran presentados en la Conferencia Anual de Ejecutivos (CADE) de 1976, en Arequipa, como nuestros "mayores males"43. En una encuesta a más de un centenar de "líderes de opinión" realizada por Richard Clinton en 1970, un 57\% ya opinó que la tasa de crecimiento de la población peruana era "mala"; para 1983 el porcentaje de los que dieron esta misma 
respuesta creció al 70\%44. La caída del régimen de Velasco Alvarado (1968-1975) abrió las puertas a una política estatal en materia de control demográfico, aprobándose en 1976 unos "Lineamientos de Política de Población en el Perú". La Constitución de 1979 incorporó una "Política Nacional de Población" en el articulado, recogiendo el principio de la "paternidad" y "maternidad responsables". Esta significaba que los padres deberían procrear solamente el número de hijos que podían sostener adecuadamente hasta que estos puedan valerse por sí mismos. Como el estándar de lo que los padres deberían proveer a la prole se había elevado considerablemente en las últimas décadas, y la edad en que ella se incorporaba al mercado de trabajo se había postergado, en la "paternidad responsable" generalmente no cabían más de dos o tres hijos. En los sectores altos y de clase media, la educación superior (entendida como la post-secundaria) para los hijos, e incluso las hijas, comenzaba a ser ya la norma; mientras en los sectores populares urbanos, debía darse a los hijos la educación secundaria completa.

La Ley Nacional de Población de 1985 se propuso conseguir un "crecimiento armónico" entre la población y la economía, así como difundir información y servicios que permitiesen una "decisión libre, informada y responsable" de las personas. Aunque hoy estos términos nos puedan sonar muy contenidos y normales (la ley rechazó, además, explícitamente, la esterilización y el aborto voluntarios), representaron un audaz avance para un Estado que no hacía más de una década había clausurado una asociación civil por dedicarse a labores de control de la natalidad. ${ }^{45}$ La acción del Estado fue empujada y acompañada por las actividades de científicos sociales del medio académico, quienes con el respaldo de agencias de cooperación extranjera, lanzaron la voz de alarma acerca del veloz crecimiento de la población en el país y esbozaron un cuadro pesimista sobre las consecuencias que tendría para el Perú no aplicar con urgencia un programa de disminución de la natalidad ${ }^{46}$.

En los años ochenta el descenso de la natalidad se hizo, sin embargo, ya notorio. También aquí cabría decir, que lo que Europa consiguió en un siglo: bajar su natalidad del 35 al 20 por mil, el Perú lo viene logrando en treinta años ${ }^{47}$. Uno de los factores de la rápida desaceleración demográfica ha sido la emigración desatada desde

Los que dijeron que la tasa de crecimiento de la población era "buena", fueron el 16\% en 1970 y sólo el 7\% en 1983. Clinton (1985), p. 137.

45 En 1975 el gobierno militar clausuró la Asociación Peruano de Protección Familiar, APPF, fundada por el Dr. Miguel Ramos Zambrano.

46 Organizaciones como la AMIDEP y el INANDEP son buenos ejemplos de estos esfuerzos. Un importante hito fue la reunión de Tarma de 1979.

47 Fue entre mediados del siglo diecinueve y mediados del veinte, que esa reducción se produjo en varias naciones europeas. Véase Cipolla (2000), pp. 102-103.
} 


\section{CUADRO 8}

EMIGRACIÓN DE PERUANOS AL EXTERIOR. SALDO MIGRATORIO, 1990-2007

\begin{tabular}{lrrrrr}
\hline Años & Hombres & $\%$ & Mujeres & $\%$ & Total \\
\hline 1990 & 24.211 & 52,0 & 22.385 & 48,0 & 46.596 \\
1991 & 36.172 & 52,9 & 32.177 & 47,1 & 68.349 \\
1992 & 25.090 & 42,7 & 33.699 & 57,3 & 58.789 \\
1993 & 37.259 & 47,2 & 41.685 & 52,8 & 78.944 \\
1994 & 24.833 & 49,7 & 25.131 & 50,3 & 49.964 \\
1995 & 18.258 & 49,4 & 18.685 & 50,6 & 36.943 \\
1996 & 18.040 & 47,5 & 19.916 & 52,5 & 37.956 \\
1997 & 20.917 & 46,3 & 24.262 & 53,7 & 45.179 \\
1998 & 26.358 & 45,3 & 31.764 & 54,7 & 58.122 \\
1999 & 25.370 & 46,7 & 28.972 & 53,3 & 54.342 \\
2000 & 32.802 & 47,5 & 36.308 & 52,5 & 69.110 \\
2001 & 35.894 & 47,1 & 40.245 & 52,9 & 76.139 \\
2002 & 55.683 & 50,7 & 54.088 & 49,3 & 109.771 \\
2003 & 75.876 & 48,3 & 81.257 & 51,7 & 157.133 \\
2004 & 104.456 & 48,1 & 112.697 & 51,9 & 217.153 \\
2005 & 123.438 & 50,3 & 121.898 & 49,7 & 245.336 \\
2006 & 145.062 & 49,8 & 146.438 & 50,2 & 291.500 \\
2007 & 116.395 & 48,6 & 123.096 & 51,4 & 239.491 \\
\hline
\end{tabular}

Fuente: Perú, República del (2008), p. 21.

los años ochenta. El fenómeno se explicó entonces por la guerra interna, la crisis económica y la inseguridad reinantes en ese momento; en los años noventa pareció remitir, por la mejoría que hubo precisamente en esos terrenos, pero desde el inicio del nuevo siglo reapareció con fuerza. En los últimos años el saldo migratorio negativo llega a rondar el uno por ciento de la población total (véase cuadro 8)

Pero el factor más decisivo para la desaceleración demográfica ha sido la reducción de la natalidad. En las últimas décadas del siglo veinte predominó una visión pesimista sobre la transición demográfica en el tercer mundo, que sostenía que mientras en los países desarrollados la reducción en la mortalidad y la natalidad habían sido la consecuencia de su propia evolución económica y social, en los del tercer mundo la mortalidad había caído por la transferencia de tecnología médica y sanitaria extranjera (junto con la ayuda económica necesaria para aplicarla). En consecuencia no cabría esperar una pronta caída de la natalidad, puesto que la moderni- 
zación económica y social no se había hecho presente en estos países. La única forma de lograr bajar la natalidad sería, otra vez, con la ayuda extranjera; pero los gobiernos del tercer mundo que décadas atrás aceptaron esta ayuda para hacer caer la mortalidad, podrían no estar dispuestos a aceptarla cuando de lo que se trataba era de reducir la natalidad ${ }^{48}$.

El gobierno peruano de los años noventa fue uno de los que sí estuvo dispuesto, e incluso por convicción propia favoreció programas de difusión de métodos anticonceptivos modernos a los que la Iglesia se había opuesto exitosamente en el pasado. En 1996 creó el Ministerio de la Mujer y de Desarrollo Humano, una de cuyas tareas fue ejecutar el Plan Nacional de Población. Las mujeres de los sectores populares urbanos se familiarizaron pronto con el uso de los anticonceptivos modernos. Entre 1977-1978 y el año 2000, el porcentaje de mujeres en unión conyugal que usaba

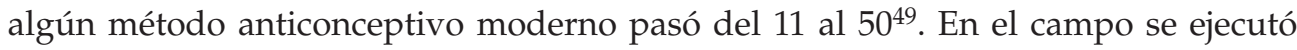
programas de esterilización de las mujeres rurales, cuya metodología ha sido después fuente de cuestionamientos ${ }^{50}$.

La demografía predice que la disminución de la mortalidad infantil, el avance en la urbanización, la difusión del modelo de familia nuclear, la mayor escolaridad de las mujeres y su envolvimiento en el empleo formal, el desarrollo de sistemas de protección a la propiedad y la salud, y la erección de sistemas eficaces de seguridad social en la vejez, resultan poderosos factores para reducir la fecundidad en una sociedad ${ }^{51}$. Ciertamente los primeros se hicieron presentes en el Perú del último cuarto de siglo. La mortalidad infantil se redujo de un nivel de 160 por mil en el quinquenio 1950-1955, a uno de 42 por mil en el de 1995-200052. La población urbana pasó de un 35\% en 1940 a un $70 \%$ en 1993. Las mujeres fueron incorporadas, al menos en el medio urbano, al sistema educativo avanzado. Para 1981 la diferencia entre el porcentaje de hombres y de mujeres que cursaba la educación Primaria, dentro del grupo de edad correspondiente, fue de solo tres puntos a favor de los varones (91.8 contra 88.8\%) y de nueve en el caso de la educación Secundaria (61.3 contra $52.3 \%)^{53}$. Para el año 2002, las mujeres con educación superior, universitaria y no

\footnotetext{
Ver Merrick (1997), pp. 177-178.

INEI (2005), pp. 94-95.

Tras la caída del régimen de Alberto Fujimori (1990-2000), una comisión parlamentaria realizó entre los años 2001-2003 una investigación sobre lo que llamó "esterilizaciones forzadas" y estableció la cifra de 331,600 mujeres campesinas esterilizadas y 25,590 hombres vasectomizados durante los años 1996-2000, bajo el programa AQV (Anticoncepción Quirúrgica Voluntaria). Aún se discute si tales actos fueron consentidos por los pobladores, o si fueron persuadidos con engaños o amenazas de perder ciertos beneficios sociales.

51 Debraj Ray, 2002, pp. 299 y ss.

52 INEI (2001b), p. 26.

53 Datos de Hernán Fernández, citados por Francke (1986), p. 304.
} 


\section{CUADRO 9}

DISTRIBUCIÓN PORCENTUAL DE LA POBLACIÓN PERUANA POR GRANDES GRUPOS DE EDAD. CENSOS DE 1940 AL 2005

\begin{tabular}{cccc}
\hline Censo de & $\mathbf{0 - 1 4}$ años & 15-64 años & 65 años a más \\
\hline $\mathbf{1 9 4 0}$ & 42,1 & 53,6 & 4,3 \\
$\mathbf{1 9 6 1}$ & 43,3 & 52,9 & 3,8 \\
$\mathbf{1 9 7 2}$ & 43,9 & 52,1 & 3,9 \\
$\mathbf{1 9 8 1}$ & 41,2 & 54,7 & 4,1 \\
$\mathbf{1 9 9 3}$ & 37,0 & 58,4 & 4,7 \\
$\mathbf{2 0 0 5}$ & 31,0 & 62,8 & 6,2 \\
\hline
\end{tabular}

Fuente: Censos nacionales 1940-2005.

universitaria, guardaban una proporción sobre el total de su género (un quinto), igual que la de los varones ${ }^{54}$. Ello fue complementado con la inclusión femenina en el sistema laboral, lo que terminó promoviendo el retraso en la edad del matrimonio de las mujeres (lo que Coale llamó la "transición maltusiana").

En cambio, los otros factores de la reducción de la fecundidad no ganaron mucho terreno en las últimas tres décadas de la historia del Perú. El empleo que creció fue sobre todo el informal, que no garantizaba pensiones de jubilación ni atención de la salud. Desde los años ochenta comenzó a desmantelarse el sistema de derechos de los trabajadores en el sector formal, abriéndose paso a una "flexibización" de las normas laborales establecidas en los mediados de siglo, a fin de volverlas compatibles con la situación de exceso de mano de obra. En la década siguiente la tendencia se acentuó, en el entendido de que un "sinceramiento" del mercado laboral (es decir, una disminución de los derechos de los trabajadores) permitiría atraer inversión a un aparato económico en ese momento paralizado.

La veloz reducción de la natalidad en el Perú, puede apreciarse en la forma cómo ha cambiado la distribución por edades de la población, desde 1940 al último censo, del 2005 (véase cuadro 9). De haber representado el 44\% de la población peruana durante la fase más aguda de la explosión demográfica, el grupo infante de 0 a 14 años, ha pasado en el último censo a representar ya menos de un tercio. 


\section{Reflexiones finales}

Una mirada superficial de la evolución económica y demográfica en el Perú del siglo veinte, podría llevar a señalar que cuando creció la población, lo hizo también la producción, y viceversa. Sin embargo, no parece poder probarse en este, como en otros casos, una causalidad lineal y simple en ese sentido. La relación entre la dinámica demográfica y el desarrollo económico tuvo en el Perú dos fases claramente diferenciadas: en la primera mitad del siglo el crecimiento demográfico estimuló el económico, al dotar con mano de obra a las industrias extractivas, así como conformar polos de demanda de medios de transporte y obras de saneamiento, que estimularon las inversiones en tales rubros. En la segunda mitad, en cambio, el crecimiento demográfico claramente desbordó la infraestructura económica existente. Como consecuencia de dicho desborde, que se sintió más pronto en la sierra, se desató una gran emigración a las ciudades y, desde la sierra hacia las otras dos regiones del país. Las condiciones de trabajo de las últimas décadas del siglo se volvieron más precarias respecto a las disfrutadas anteriormente, y el Estado tuvo que salir a dar empleo a una parte importante del excedente laboral, como una forma de apaciguar las turbulencias sociales y políticas creadas por el desempleo.

Pasada la mitad del siglo, la expandida población del país, que para entonces disfrutaba de un dinámico nivel de empleo gracias a las actividades extractivas para la exportación, se convirtió también en un señuelo interesante para la industria de bienes de consumo. El proyecto de fomento de la industrialización por sustitución de importaciones desarrollado en el Perú desde los años sesenta, podría entenderse así como una consecuencia lógica de esta oportunidad abierta por la evolución demográfica. Sin embargo, en la década siguiente ocurrió la crisis del sector exportador, pasmando dicho proyecto.

Un punto en el que hemos puesto énfasis es en resaltar la acción y la iniciativa local para orientar la política de población. Si bien no dejamos de reconocer la importancia que la influencia y la presión de la cooperación extranjera tuvieron para reducir la mortalidad, primero, y la natalidad después, sin la colaboración local los resultados no se habrían conseguido. La infraestructura del Estado en caminos, escuelas y personal, así como su compromiso con la meta de la política demográfica fueron claves para la trayectoria de la población. Si la caída de la mortalidad no fue más precoz (como en otros países latinoamericanos) se debió a la carencia de una mínima infraestructura estatal antes de 1900, al tiempo que si la reducción de la natalidad tuvo que esperar hasta una fecha tardía (en el contexto latinoamericano) como los avanzados años setenta, fue por la renuencia del Estado local a aceptar esa reducción como una "buena" política de población. 
Finalmente, lo sucedido podría asemejarse a las parábolas del aprendiz de brujo. Al comienzo del siglo, aproximadamente hasta 1930, se luchó por sacar a la gente del campo y de su economía autárquica, a fin de estimular la formación de un mercado laboral, y de procurar que las entonces promisorias actividades extractivas agrícolas y mineras pudieran estabilizar una masa laboral que hiciese viable su economía. Después de 1930 se consiguió por fin fijar a esta fuerza laboral, para lo que fue importante una serie de beneficios en salud, educación y jubilación que hicieron del trabajo asalariado una alternativa deseable y preferible al auto empleo en el campo. Estos beneficios respondieron, a su vez, a las presiones desplegadas por las nuevas organizaciones políticas que agruparon a la clase trabajadora y urbana desde aproximadamente 1930.

Después de 1960, la población del campo siguió desafiliándose de sus organizaciones agrarias, alimentada por las expectativas que la masificación de la educación les había abierto, a pesar de que por entonces no hacía ya más falta su mano de obra en el mercado. El desajuste creado por el excedente laboral en las ciudades, y en el propio campo, provocó serias crisis políticas en los años setenta a noventa. La reforma agraria de 1962-1979 fue un intento fallido de enfrentar la existencia de un excedente laboral, redistribuyendo la cada vez más escasa tierra cultivable del país. En cierta forma, se estaba cosechando de las políticas pro-natalistas y pro-emigración del campo que se había sembrado en los inicios del siglo.

En los años noventa se retiró parte de los beneficios laborales que en otra etapa se concedieran a los trabajadores urbanos y se montó programas de ayuda social y control de la natalidad, que procuraron salir al campo y no quedarse únicamente en los centros urbanos como hasta entonces. La población urbana reaccionó reduciendo su natalidad y la emigración desde la sierra pareció también disminuir.

El veloz crecimiento de la población del país en el siglo veinte, continuación del proceso de "recuperación demográfica" del siglo anterior, desbordó las estrechas posibilidades de empleo de un territorio con pocas tierras cultivables y con una economía básicamente especializada en la exportación de materias primas, como secuela de su pasado histórico. La esperanza de que — siguiendo las ideas de Ester Boserup - el propio empuje demográfico sacara a la economía de este patrón, chocó con la rigidez de los factores productivos para adaptarse, con la velocidad que el proceso requería, al nuevo esquema de tierra escasa y trabajo abundante. La remisión del crecimiento demográfico en los últimos lustros -sobre todo ahora, que el flujo de mano de obra que sale al mercado comienza a disminuir - debe funcionar como una tregua para que el aparato económico pueda ajustarse a la nueva realidad de población. 


\section{Bibliografía}

BCRP (2004): Memoria del Banco Central de la República del Perú 2004, Lima, BCRP. -(2006), Memoria del Banco Central de la República del Perú 2006, Lima, BCRP.

BONFIGLIO, Giovanni (2001), La presencia europea en el Perú: con estudios de casos, Lima, Congreso de la República del Perú.

BONILLA, Heraclio (1974): El minero de los Andes, Lima, IEP.

BOSERUP, Ester (1984): Población y cambio tecnológico: estudio de las tendencias a largo plazo. Barcelona, Crítica.

CABALLERO, José María (1981): Economía agraria de la sierra peruana, antes de la reforma agraria de 1969, Lima, IEP.

CENTRO DE ESTUDIOS DE POBLACION Y DESARROLLO (1972): Informe Demográfico Perú 1970, Lima, CEPD.

CEPAL (2006), Anuario estadístico de América Latina y el Caribe 2005, Santiago de Chile, CEPAL.

-(2008), Anuario estadístico de América Latina y el Caribe 2007, Santiago de Chile, CEPAL.

CHOCANO, Eduardo, ZULETA, Edilberto y VIDAL, Carlos (1925), El desenvolvimiento comercial e industrial del Perú. Lima, Sociedad Nacional de Industria.

CIPOLLA, Carlo (2000): Historia económica de la población mundial, Barcelona, Crítica.

CLARK, Colin (1970): Population Growth and Land Use, Londres, MacMillan-St Martin's.

CLINTON, Richard (1985): Población y desarrollo en el Perú, Lima, Universidad de Lima.

COALE, Ansley (1978): Population Growth and Economic Development: the Case of Mexico, Foreign Affairs 56.

COALE, Ansley y HOOVER, Edgar (1965): Crecimiento de la población y desarrollo económico, México, Limusa-Wiley.

CONTRERAS, Carlos (1988), Mineros y campesinos en los Andes. Economía campesina y mercado laboral en la sierra central peruana, siglo XIX, Lima, IEP.

-(2004): El aprendizaje del capitalismo. Estudios de historia económica del Perú republicano, Lima, IEP

COTLEAR, Daniel (1989): Desarrollo campesino en los Andes. Cambio tecnológico y transformación social de la sierra del Perú, Lima, IEP.

DEERE, Carmen (1992): Familia y relaciones de clase: el campesinado y los terratenientes en la sierra norte del Perú, 1900-1980, Lima: IEP.

DEWIND, Adrian (1977): Peasants become miners; the evolution of industrial mining systems in Peru, Manusc. (Biblioteca de la PUCP).

EGO AGUIRRE, Julio (1911): Memoria del Ministro de Fomento presentada al Congreso Ordinario de 1911, Lima. 
FERRERO, Raúl (1984-1993 [1941]), “Integración económica del Perú y defensa de sus riquezas", en Obras completas, vol. 4, Lima, Concytec, pp. 229-251.

-(1984-1989 [1976]), "Recursos humanos", en Obras completas, vol. 4, Lima, Concytec; pp. 487-504.

FERRERO, Rómulo (1938): Tierra y población en el Perú: la escasez de tierras cultivadas en el Perú y sus consecuencias, Lima, Banco Agrícola del Perú.

-(1963), "El desarrollo de la economía nacional durante los últimos veinticinco años", Lima. S.e.

FRANCKE, Marfil (1986): “Mujer, población y desarrollo", en GUERRA GARCIA, Roger, (ed.), Problemas poblacionales peruanos II, Lima, AMIDEP, pp. 299-352.

GARCIA, José (1912), Memoria del Ministro de Fomento presentada a la Legislatura Ordinaria de 1912 por José M. García, Lima.

GARLAND, Alejandro (1905): Reseña industrial del Perú, Lima, Ministerio de Fomento.

GERBI, Antonello (1941): El Perú en marcha: ensayo de geografía económica, Lima, Banco Italiano.

GONZALEZ, Michael (1985): Plantation Agriculture and Social Control in Northern Peru, 1875-1933, Austin: Texas University Press.

GONZALEZ, Oswaldo (1952): Perú: población y agricultura, Lima, Librería Internacional del Perú.

GRAÑA, Francisco (1908): El problema de la población en el Perú. Inmigración y autogenia, Lima, Tipografía El Lucero.

GUERRA GARCIA, Roger (1986) (ed.): Problemas poblacionales peruanos II, Lima, AMIDEP.

HUAMÁN, Pacífico (1990): “Remuneraciones, inflación y pobreza”, en Moneda, vol. II, 18, Lima, BCRP; pp. 40-43.

HUNT, Shane (1980): “Evolución de los salarios reales en el Perú, 1900-1940", en Economía, vol. III, 5, Lima, Departamento de Economía de la PUCP; pp. 83-113.

INSTITUTO NACIONAL DE ESTADISTICA (1983): Estimación y proyección de población del país, 1950-2025, urbana y rural 1970-1995, Lima, INE.

-(1988): Cuentas Nacionales 1950-1987. Lima, INE.

INSTITUTO NACIONAL DE ESTADISTICA E INFORMATICA (1993): Compendio estadístico del Perú 1992-1993, Lima, INEI.

-(1997): Compendio estadístico del Perú 1995-1996, Lima, INEI.

-(2001): Encuesta demográfica y de salud familiar (ENDES) 2000, Lima, INEI.

-(2001b): Perú: estimaciones y proyecciones de población, 1951-2000, Boletín de Análisis Demográfico 35, Lima, INEI.

-(2006): Compendio estadístico del Perú 2005, Lima, INEI.

-(2007): Perú. Encuesta Demográfica y de Salud Familiar. Endes continua 2004-2005, Lima, INEI-USAID-Measure DHS+. 
KELLEY, Allen y SCHMIDT, Robert (2001), "Economic and Demographic Change: a Synthesis of Models, Findings and Perspectives", en BIRDSALL, Nancy, KELLEY, Allen C. y SINDING, Steven, Population Matters: Demographic Change, Economic Growth and Poverty in the Developing World, Oxford, Oxford University Press; pp. 67-105.

KUZNETZ, Simon (1974): Población y crecimiento económico, San José de Costa Rica, Celade.

LESEVIC, Bruno (1986): La recuperación demográfica en el Perú del siglo XIX, Lima, INANDEP.

LEWIS, Arthur (1963): "El desarrollo económico con oferta ilimitada de trabajo", en AGARWALA, A. N., La economía del subdesarrollo, Madrid, Tecnos; pp. 333-373.

LONG, Norman y ROBERTS, Bryan (2001): Mineros, campesinos y empresarios en la sierra central del Perú, Lima, IEP.

MADDISON, Angus (2002): La economía mundial: una perspectiva milenaria, Madrid, Mundi prensa.

MARIE, Victor (1905): “La agricultura y la economía rural del valle de Chicama: Memoria presentada al Ministerio de Fomento", en Boletín Agrícola, 10-11, Arequipa; pp. 276-286.

MARTINEZ ALIER, Juan (1974): Los huacchilleros en el Perú, Lima: IEP y Ruedo Ibérico.

MERRICK, Richard (1997): “La población de América Latina, 1930-1990", en BETHELL, Leslie, ed., Historia de América Latina. Vol. 11: Economía y sociedad desde 1930, Barcelona, Crítica, pp. 165-215.

MINISTERIO DE AGRICULTURA (1990): Boletín Estadístico del Sector Agrario 1989. Lima, MA.

MINISTERIO DE HACIENDA (1947): Anuario Estadístico del Perú, 1944-1945. Lima, $\mathrm{MH}$.

NORTON, Seth (2002): Population Growth, Economic Freedom and the Rule of Law, PERC Policy, Series 24.

OTERO, Hernán (1997), (comp.): Poblaciones argentinas: Estudio de demografía diferencial, Buenos Aires, Propiep.

PAÚCAR, Héctor (1997): Determinantes de la evolución de los salarios reales en el largo plazo, Lima Metropolitana, Tesis de Ciencias Sociales, Lima, PUCP.

PELOSO, Vincent (1999): Peasants and Plantations: Subaltern Strategies of Labor and Resistance in the Pisco Valley. Durham: Duke University Press.

PERU, REPUBLICA DEL (2008): Estadísticas de la Migración Internacional de Peruanos, 1990-2007, Lima, OIM.

PORTOCARRERO, Felipe, BELTRAN, Arlette y ROMERO, María Elena (1992): Compendio estadístico del Perú, 1900-1990, Lima, Centro de Investigaciones de la Universidad del Pacífico. 
PRESIDENCIA DEL CONSEJO DE MINISTROS (1993): Perú: Informe nacional sobre población y desarrollo, Lima, PCM.

RAY, Debraj (2002): Economía del desarrollo, Barcelona, Antoni Bosch.

RODRIGUEZ DOIG, Enrique (1986): El camino de los enganchados: un estudio de los campesinos chotanos para la Sociedad Agraria Pucalá, Lima, Fomciencias.

RODRIGUEZ DULANTO, Manuel (1907): El primer problema de la agricultura nacional, Lima, La Industria.

SALAZAR-SOLER, Carmen (2006): Supay Muqui, Dios del socavón, Lima, Congreso de la República del Perú.

SANCHEZ-ALBORNOZ, Nicolás (1973): La población de América Latina. Desde los tiempos precolombinos al año 2000, Madrid, Alianza.

SEMINARIO, Bruno y BELTRAN, Arlette (1998): Crecimiento económico en el Perú, 1896-1995. Nuevas evidencias estadísticas, Lima, Centro de Investigaciones de la Universidad del Pacífico.

SIMON, Julian (1991): Population and Development in Poor Countries: Selected Essays, Princeton, Princeton University Press.

THORP, Rosemary (1998): Progreso, pobreza y exclusión. Una historia económica de América Latina en el siglo XX, Nueva York, Banco Interamericano de Desarrollo y Unión Europea.

THORP, Rosemary y BERTRAM, Geoffrey (1985): Perú 1890-1977. Crecimiento y políticas en una economía abierta, Lima, Mosca Azul, Fundación F. Ebert y Universidad del Pacífico.

VARILLAS, Alberto y MOSTAJO, Patricia (1990): La situación poblacional peruana, Lima, INANDEP.

WEBB, Richard y FIGUEROA, Adolfo (1975): La distribución del ingreso en el Perú, Lima, IEP.

WICHT, Juan (1980): “La situación demográfica del Perú", en AMIDEP, Problemas poblacionales peruanos, Lima, AMIDEP, pp. 17-93.

-(1986): "Realidad demográfica y crisis de la sociedad peruana", en GUERRA GARCIA, Roger, (ed.): Problemas poblacionales peruanos II, Lima, AMIDEP, pp. 7-115. 